\title{
Bienvenido, papá
}

\section{Por Carlos Fernández Imitola ${ }^{1}$}

Caminaba solo, lento y desgarbado con una pesada maleta roja que le tensaba el brazo. Había demasiadas chicas lindas deambulando por las calles y los taxis también pasaban veloces y ocupados. Tenía en el bolsillo un billete de veinte mil pesos, falso y arrugado; de la cara.

¿De qué mierda se reía?

No tenía la menor idea, pero por más que se frotaba los labios con el reverso de la mano no conseguía borrarla de allí. Témele a un hombre que es capaz de sonreír siempre -pensó, extrañamente decididoincluso cuando la mierda le llega al cuello.

No supo porqué, pero recordó al padre y la última vez que lo vio. Fue dentro de un bus en medio de un torrencial aguacero. Estaba sentado mirando el paisaje móvil y mojado a través de la ventana cuando escuchó su nombre. Sus dos nombres de pila. De inmediato supo que era él, aunque la voz, ahora lánguida y ronca, no era la misma.

Sólo él y su madre lo llamaban por sus dos nombres, claro que su madre sólo lo hacía cuando se trataba de algo verdaderamente serio, cuando la situación era tensa y había algo de qué preocuparse.

De cualquier forma no le gustaba que lo llamaran por su segundo maldito nombre, se avergonzaba, le parecía ridículo, pasado de moda, con una sonoridad estridente.

Volteó la cabeza para mirar y ahí estaba: más viejo, más flaco, cabello largo, ojeroso, acabado, con la mierda hasta el cuello. Daba ganas de llorar. Entonces su padre esbozó una sonrisa lamentable, huérfana de dientes. Le faltaban por lo menos cuatro y sin embargo se reía. ¿De qué mierda se reía su padre?

La esperanza no es lo último que se pierde, pensó atemorizado, sino los dientes.

1 Profesional del Programa de Lingüística y Literatura de la Universidad de Cartagena. En el 2003 publicó el libro de cuentos El Siguiente, por favor, con el que ganó el Premio Distrital de Cartagena en el 2002. En el 2004 fundó el grupo “Bostezo Teatro" para el que escribió y dirigió varias obras. 
-¿Para dónde vas?- preguntó el padre.

-Para la Universidad- contestó, y en el acto recordó lo que éste le decía cuando era pequeño: "Sólo los hombres a los que les faltan huevos van a la universidad".

- ¿Y tú, hasta dónde llegas?- devolvió la pregunta a su vez, intentando ser cortés.

-¿Yo?, hasta donde escampe- contestó, sin el menor asombro.

Hubo un silencio que duró minutos. Miró hacía la ventana para contemplar una vez más el paisaje mojado. Cuando volvió a girar la cabeza, su padre y su sonrisa sin dientes ya no estaban.

Puso la maleta roja en el piso y sacó el billete falso del bolsillo. Lo observó detalladamente, era falso, de calle, casi de juguete.

“¿Cómo mierda no me di cuenta?”, pensó irritado.

Y no lo habría descubierto jamás de no ser porque unos minutos después de verse desamparado en la calle intentó comprar en una cigarrería algo para comer. El dueño, un tipo obeso con facciones orientales, después de revisarlo minuciosamente a contraluz le señaló el letrero: "Todo billete falso se rompe", e hizo ademán de romperlo.

Él le suplicó que no lo hiciera, porque sabía dónde se lo habían dado y aún podía devolverlo. El dueño insistió en señalarle el letrero y amagó una vez más con romper el billete. Entonces no tuvo más remedio que sacar coraje de quién sabe dónde y amenazarlo, diciéndole que volvería acompañado y que él y sus amigos le harían pedazos el maldito local.

“Venga, hijo de puta, aquí lo espero", contestó el dueño.

Pero cuando viró, resignado y tembloroso, sintió el golpecito del billete envuelto sobre la nuca.

"Métaselo por el culo", dijo el dependiente.

Entonces lo recogió del piso, lo desenvolvió, se lo metió en el bolsillo y salió a la calle nuevamente.

Había encontrado la pesada maleta en la puerta del apartamento al regresar de la biblioteca, sin una nota de explicación. Dentro estaba el 
total de su ropa, los zapatos, unos cuantos libros y en la corredera de afuera un CD recién comprado. Introdujo la llave en la puerta, pero la cerradura había sido cambiada. Oprimió el timbre varias veces, tocó con los nudillos durante un rato, procurando no hacer demasiado escándalo para no alertar a los vecinos. Le marcó al celular, pero Sara no contestó. No tenía la más remota idea de lo que estaba pasando: La maleta con sus cosas, el cambio de cerradura, ¿por qué diablos no le contestaba el teléfono?

Decidió bajar y salir del edificio para marcarle desde un número diferente, tal vez así contestaría. Antes de dirigirse a una cabina atisbó para ver si notaba algún movimiento a través de la ventana. Tomó unas piedrecillas del suelo y las arrojó contra el vidrio. Desistió y entró a la cabina y le marcó al celular infinitas veces durante quince minutos, pero tampoco encontró respuesta. De manera que dejó un mensaje en el buzón. ¿Qué había pasado? ¿Acaso Sara había descubierto alguno de sus secretos? Y si así había sido, ¿cuál de todos?

No supo porqué, pero se sintió culpable. Había tantas cosas en su presente y pasado que lo hacían sentir culpable, tantas cosas que lo avergonzaban, cosas que había hecho, cosas que había dejado de hacer. Se sentía culpable siempre. No se trataba de grandes mentiras o crímenes atroces, sino de cosas nimias, pero punzantes, pequeñas omisiones, cosas que la gente da por sentadas, malos entendidos respecto a sí mismo que él asumía como propios, detalles engorrosos que lo atormentaban por las noches y le apuñalaban el sueño.

"Maldito sentido cristiano de la culpa", gritó en silencio.

El sentido de la culpa le venía de parte de la madre, sin duda, la debilidad que durante años le había inculcado, instada por el temor de que algún día llegara a parecerse al gañán del padre. Era tanta la culpa que cuando llegaba ebrio a casa la madre le ordenaba que pidiera de inmediato disculpas a Dios y al día siguiente a sus amigos: “Tú no sabrás porqué, pero ellos sí”, le decía seriamente.

En los pocos años que vivió con el padre, éste solo atinó a darle un consejo, breve y contundente: "No des ni recibas consejos". El resto de cosas que intentó enseñarle eran lecciones prácticas: cómo embaucar a una mujer, cómo robarse un libro de una biblioteca o una fruta de un supermercado, cómo meter un billete falso.

Esta última lección la recordaba, ahora, mientras caminaba: "Debes conseguir un billete de una denominación mayor a la del billete falso, 
entras a una tienda, compras cualquier cosa y pagas con ese billete, mientras sostienes oculto entre los dedos el falso. Si tienes suerte y entre las vueltas hay un billete de igual valor al falso, el trabajo está hecho. Sacas el billete de entre los dedos y le dices al dependiente que él te lo acaba de dar. Eso es todo, siempre funciona".

Se lo había dicho y se lo había demostrado unos minutos después en una tienda del barrio. Sí, el padre era un hombre práctico. No había necesitado ir a la universidad para comprender que la vida debe asumirse como una praxis y no como una moral. La noche antes de largarse entró a su cuarto y le dijo: "No tengo dinero que dejarte, sin un peso te encontrarás en muchas ocasiones, pero quiero que pienses que tu único capital está en tu ingenio y en la estupidez de los demás. Sobre ésta última y sobre el crimen se han cimentado las grandes fortunas de la humanidad, nunca lo olvides".

Y ahora mientras lo recordaba, se puso a pensar que su personalidad negada era una conjugación de la de la madre y la del padre. La madre le había dotado de un corazón generoso y compasivo; el padre le había dejado por herencia una mente de rata. Sólo que él estúpidamente había generado una lucha interna entre ambos polos que había opacado la influencia del padre y no le permitía avanzar. Pensó de pronto que la mejor forma de asumir las dos influencias era complementándolas. El no sería su padre, no. Si él fuera su padre habría levantado la puerta a patadas y sería su mujer la que estuviera recorriendo las calles de Bogotá con una maleta en la mano. Si fuera su padre habría cogido por el cuello al maldito tendero y lo habría hecho tragar a pedacitos el billete de veinte mil pesos. Pero él no era su padre, él sí había ido a la universidad. La sonrisa que no podía desprenderse de la cara, por fortuna, aún tenía dientes.

Desde luego tampoco era su madre, no tenía por que disculparse o dar explicaciones a los demás, ya no se sentaría culpable, ni con la necesidad de aclarar frente a otros sus aspectos más oscuros. ¿A razón de qué? ¿Quién mierda lo hacía? Ya no andaría más torturándose con la existencia o no existencia de Dios. ¿Cuál Dios? Si Dios existía era problema de él, y no suyo. Su problema era que él existía y que se encontraba caminando solo, sosteniendo una maleta pesada, con un billete falso como único capital por las calles de una gélida ciudad.

De repente decidió cambiar de dirección.

“Es mejor ir al norte que al sur", se dijo, y viró de inmediato. 
Tal vez más tarde volvería al edificio, tocaría de nuevo e intentaría conciliar con su mujer, o de ser necesario tumbaría la puerta a patadas para saber de una vez por todas qué diablos pasaba. Más tarde lo decidiría. De pronto, mientras pensaba en lo que de momento iba a hacer, se precipitó sobre el asfalto bogotano una lluvia exigua, que poco a poco fue acelerando en su ímpetu.

La gente empezó a correr despavorida de un lado para otro, tratando de guarecerse en algún lugar. Algunos más precavidos desenfundaban sus paraguas y otros extendían periódicos, abriendo ambos brazos como mártires crucificados. Él corrió como pudo, arrastrando la pesada maleta. En un cruce tropezó de frente con una mujer horrible, la más horrible que había visto en su vida, que también corría. En la esquina, cerca a un semáforo en rojo, un taxi vacío se detuvo. Sin pensarlo, avanzó hacia él, abrió la puerta y entró.

Leyó el nombre del taxista en la cartulina donde además estaban escritas las tarifas. "Ese sí es un buen nombre", pensó. "Así debería llamarme yo".

De una corredera externa de la maleta sacó el CD, lo destapó y se lo pasó al conductor.

"Póngame la canción número seis", sugirió.

La canción era The Traitor, de Leonard Cohen. La canción que Sara solía ponerle cuando acababan de hacer el amor, de la cual él no entendía nada, pero se sabía de memoria.

El taxi avanzaba presuroso hacía el norte, mientras la gente en la calle se desgañitaba inútilmente estirando los brazos por conseguir un taxi vacío. Los buses también pasaban repletos, a reventar.

"I touch her here and there/I know my place", cantaba al unisono con Leonard Cohen. ¿¿Hasta dónde lo llevo?” le preguntó el taxista.

"I kiss her open mouth and I praise her beauty, and people call me traitor to my face", seguía cantando abstraído. Los vendedores de paraguas hacían su agosto en las esquinas, Lonard Cohen y su voz, desgarrada como la lluvia, continuaban inundándolo todo. Todo. La voz de Leonard y los violines de su banda se deslizaban suavemente a través de su mente, como las gotas de lluvia que lamían con sus delgadas lenguas el parabrisas del taxi, pero a diferencia de éstas la notas de Cohen no podían ser fácilmente removidas. 
"Hasta dónde lo llevo", volvió a preguntar el taxista, frenando en un semáforo, girando el cuerpo y mirándolo a los ojos.

"Hasta donde escampe", contestó el hombre, sin el menor asombro. 